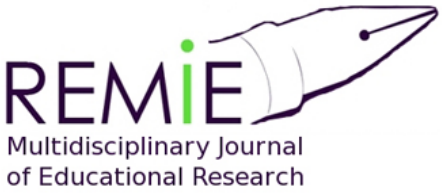

Multidisciplinary Journal of Educational Research
Hipatia Press

www.hipatiapress.com

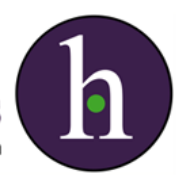

Instructions for authors, subscriptions and further details:

http://remie.hipatiapress.com

\title{
Ecologías del Aprendizaje. Educación Expandida en Contextos Múltiples
}

Teresa Morlá Folch ${ }^{1}$

1) Universitat Rovira i Virgili.

Date of publication: June $15^{\text {th }}, 2019$

Edition period: June 2019 - October 2019

To cite this article: Morlà Folch, T. (2019). Ecologías del Aprendizaje.

Educación Expandida en Contextos Múltiples [Review of the book]. REMIEMultidisciplinary Journal of Educational Research, 9(2), XXX - XXX. doi:10.17583/remie.2019. 4167

To link this article: http://dx.doi.org/doi:10.17583/remie.2019.4167

\section{PLEASE SCROLL DOWN FOR ARTICLE}

The terms and conditions of use are related to the Open Journal System and to Creative Commons Attribution License (CC-BY). 
REMIE - Multidisciplinary Journal of Educational Research Vol. 9

No. 2 June 2019

\section{Review}

Bautista Martínez Rodriguez, J. \& Fernández Rodríguez, E. (Comps.) (2018). Ecologías del Aprendizaje. Educación Expandida en Contextos Múltiples. Madrid: Morata. ISBN: 978-84-7112-874-4.

Ante el pretexto del nuevo sentido democrático de la ciudadanía en las experiencias educativas es relevante comprender los nuevos entornos de aprendizaje y la socialización en los mismos. Actualmente, los proyectos educativos están conectando entornos, contextos y escenarios, es decir, se rompe con aquella visión reducida del aprendizaje centrada únicamente en el ámbito formal y académico. Frente esta realidad social, diferentes personas investigadoras motivadas por los cambios sociales y retos educativos en la Era Digital comparten la Red Universitaria de investigación e Innovación Educativa (REUNI+D). Fruto de este trabajo entre investigadoras e investigadores se aporta un conocimiento detallado sobre Ecologías de Aprendizaje. El libro está compuesto por quince capítulos, estructurados en cuatro partes, correspondientes a las dimensiones o perspectivas de las Ecologías de Aprendizaje.

En la primera parte se desarrollan las ecologías personales del aprendizaje en espacios colectivos de experimentación autónoma. Por ello, se aborda la construcción de la identidad a través de cuatro casos de estudio en el contexto universitario y en el de educación infantil. En un mundo caracterizado por las tecnologías digitales y las redes sociales, uno de los conceptos que emerge y se desarrolla en el libro es el de 'aprendizaje trilógico'. Este aprendizaje está inmerso en una filosofía de creación de nuevos artefactos materiales y conceptuales para el fomento, descubrimiento e innovación deliberada del conocimiento colaborativo y sistemático.

La segunda parte se denomina: ecologías de recursos, la cual hace referencia a las mediaciones sociales de culturas y contextos. En este bloque 


\section{Morlà-Foch-Ecologías del Aprendizaje [Book Review]}

se destacan los espacios creativos a través de la educación musical y lecturas compartidas. Igualmente, se subraya el papel de la alfabetización y la educación transmedia dentro de instituciones formales en jóvenes universitarios, concretamente se discute la relación entre la alfabetización transmedia, la construcción de ciudadanía y las mediaciones del aprendizaje desde una visión creativa. En este bloque, también se hace referencia a la tecnología en relación a la teoría feminista, y como tema central se destacan las experiencias de desigualdad en las TIC.

En la tercera parte, ecologías comunitarias, se subraya el carácter social de tres comunidades de prácticas. En esta parte, se destaca el cuestionamiento del sentido de la universidad en nuestra sociedad, enfatizando en el compromiso social de los propios estudiantes. También se desarrolla una experiencia en una escuela abierta a niños entre 1 y 6 años en un contexto comunitario. El estudio de caso planteado a educación infantil enriquece la comprensión de la actividad de aprendizaje expansivo, destacando las actividades colectivas, así como, el trabajo organizacional a través del enfoque pedagógico de la escuela.

Y la última parte, ecologías de saberes, en que se detallan cuatro contextos donde se desarrollan proyectos en espacios de trabajos creativos, así como, la experimentación de metodologías participativas orientadas a la transformación y al desarrollo de la identidad comunitaria. Entre las experiencias concretadas se destaca el voluntariado internacional como agentes potenciadores del intercambio de saberes. Las otras experiencias de este apartado apelan a un tema central en el debate científico actual como es la creatividad. También se subraya una experiencia de formación de formadores, basada en grupos cooperativos compuestos por grupos de personas en situación de desempleo prolongado.

A través de la multiplicidad de experiencias desarrolladas en el libro, se muestran escenarios diversos: institucionales, artísticos, socio-educativos, en redes sociales, en tecnologías en expansión, comunicativos, profesionales, etc. Enfatizando en la interacción en los grupos y comunidades diversas a través de las cuales nos sumerge ampliamente a las implicaciones teóricas y epistemológicas del concepto Ecologías del Aprendizaje. Se realiza un estudio exhaustivo del carácter social, comunitario, participativo e interactivo de diferentes experiencias educativas, aportando claves para 
afrontar los retos de nuestros tiempos en clave educativa. En definitiva, a lo largo de los diferentes capítulos se proporciona una visión general muy apropiada para plantear nuevas investigaciones educativas, especialmente para el avance científico en relación a la interacción entre la educación formal, informal y las nuevas tecnologías.

Teresa Morlà Folch, Universitat Rovira i Virgili teresa.morla@urv.cat 